\title{
Histamine release upon adenosine 5'-monophosphate (AMP) nasal provocation in allergic subjects
}

\author{
R Polosa, C Pagano, G Prosperini, J L Low, D Dokic, M K Church, N Crimi
}

\begin{abstract}
Background-Nasal provocation with adenosine 5'-monophosphate (AMP) elicits nasal symptoms in subjects with rhinitis. Histamine released from mast cells may play a part in AMP induced nasal responses.

Methods-Symptoms of rhinitis were recorded and histamine release in the fluid obtained by nasal lavage after AMP, guanosine 5'-monophosphate (GMP), and placebo instillations was measured in nine subjects with allergic rhinitis and nine non-allergic controls in a double blind, randomised, placebo controlled study.

Results-No symptoms or significant increases in histamine were observed after GMP and placebo challenge. Significantly higher levels of histamine were seen in the nasal lavage fluids of allergic subjects following AMP challenge than in nonallergic controls, the median (range) histamine concentration increasing from the baseline value of $1.62(0.44-6.99) \mathrm{ng} / \mathrm{ml}$ to $6.45(0.81-16.17) \mathrm{ng} / \mathrm{ml}$ at three $\mathrm{min}-$ utes. No increase in histamine levels was seen in the non-allergic subjects in whom the median histamine concentration was $1.13(0.29-4.25) \mathrm{ng} / \mathrm{ml}$ at baseline and 0.97 (0.31-5.89) $\mathrm{ng} / \mathrm{ml}$ three minutes after AMP challenge.
\end{abstract}

Apparato Respiratorio, Università di Catania, Via Passo Gravina 187, 95125 Catania, Italy

R Polosa

C Pagano

G Prosperini

N Crimi

University Medicine, Southampton General Hospital, University of Southampton,

Southampton

SO16 6DY, UK

J L Low

D Dokic

M K Church

Correspondence to: Dr R Polosa, University Medicine, Level D, Centre Block, Southampton General Hospital, Southampton SO16 6YD, UK

Received 24 June 1998 Returned to author 28 August 1998

Revised manuscript received

30 October 1998

Accepted for publication

25 November 1998

Adenosine is a naturally occurring purine nucleoside which may have an important role in allergic diseases. ${ }^{12}$ The potential for its involvement in rhinitis was based on our early observation that nasal provocation with adenosine 5'-monophosphate (AMP) reproduced many of the symptoms of rhinitis in a dose dependent fashion. ${ }^{3}$ Adenosine may elicit nasal responses by enhancing histamine release from immunologically activated human mast cells and basophils. ${ }^{4-6}$
Indeed, mast cell derived histamine may be responsible for the adenosine induced symptoms of rhinitis as pretreatment with the potent anti- $\mathrm{H}_{1}$ receptor antagonist, cetirizine, completely abolished these symptoms. ${ }^{3}$ More direct evidence that histamine is released from airway mast cells in response to adenosine comes from our work in which asthmatic airways responded to endobronchial instillation of AMP with a prompt rise in histamine levels in the bronchoalveolar lavage fluid. ${ }^{7}$

Histamine release from activated mast cells is also likely to take place in the nose in vivo following adenosine challenge. To test this hypothesis we have used a model of nasal provocation with purine nucleotides and monitored histamine levels in the nasal lavage fluid of allergic and non-allergic subjects. The subjects participated in a double blind, randomised, placebo controlled crossover study to compare the abilities of AMP, guanosine 5'-monophosphate (GMP), and placebo (saline) to induce changes in nasal symptoms and histamine release. The nasal provocations with GMP and saline were used as controls to test for the specificity of the response.

\section{Methods}

SUBJECTS

Nasal challenge was performed in nine allergic rhinitic subjects (six men; age range 14-36 years) and nine non-allergic controls (four men; age range $18-41$ years). The non-allergic controls had no previous history of allergic symptoms and skin tests were negative (table 1). None of the subjects studied was taking any form of medication at the time of study and none had ever received specific immunotherapy. None of the subjects had experienced an upper respiratory illness in the six weeks before the study. All visits to the laboratory were carried out at the same time of day and outside the pollen season. The study was approved by the Ascoli-Tomaselli Hospitals ethical committee and all subjects gave their informed consent.

\section{STUDY DESIGN}

Subjects attended on three occasions, separated by at least five days, and were randomly allocated to receive nasal challenge with single doses of either AMP (6.5 mg), GMP (6.5 mg), or placebo (normal saline) in a double blind crossover study design. At each visit sequential nasal lavages were performed bilaterally five times prior to nasal challenge. Further nasal lavages were performed at 3, 5, 10, 15, 30 and 
Table 1 Characteristics of subjects and individual nasal symptom scores on the three study days

\begin{tabular}{|c|c|c|c|c|c|c|c|c|c|c|c|c|c|c|c|c|}
\hline \multirow{2}{*}{$\begin{array}{l}\text { Subject } \\
\text { no. }\end{array}$} & \multirow[b]{2}{*}{ Age } & \multirow[b]{2}{*}{ Sex } & \multirow[b]{2}{*}{ Atops } & & \multicolumn{4}{|c|}{ AMP study day } & \multicolumn{4}{|c|}{ GMP study day } & \multicolumn{4}{|c|}{ Placebo study day } \\
\hline & & & & & Sneezing & Rhinorrhoea & Blockage & Pruritus & Sneezing & Rhinorrhoea & a Blockage & Pruritus & Sneezing & Rhinorrhoea & Blockage & Pruritus \\
\hline 1 & 26 & $M$ & + & & 1 & 1 & 0 & 1 & 0 & 0 & 0 & 0 & 0 & 0 & 0 & 0 \\
\hline 2 & 30 & $M$ & + & & 0 & 0 & 2 & 1 & 0 & 0 & 0 & 1 & 0 & 0 & 0 & 0 \\
\hline 3 & 17 & $M$ & + & & 3 & 1 & 0 & 1 & 0 & 0 & 0 & 0 & 1 & 0 & 0 & 0 \\
\hline 4 & 26 & $M$ & + & & 0 & 0 & 2 & 2 & 0 & 0 & 0 & 1 & 0 & 0 & 1 & 1 \\
\hline 5 & 14 & $M$ & + & & 3 & 3 & 1 & 2 & 0 & 0 & 0 & 0 & 0 & 0 & 0 & 1 \\
\hline 6 & 36 & $\mathrm{~F}$ & + & & 3 & 3 & 1 & 3 & 0 & 0 & 0 & 2 & 0 & 0 & 0 & 0 \\
\hline 7 & 15 & $\mathrm{~F}$ & + & & 3 & 2 & 2 & 3 & 0 & 0 & 0 & 0 & 0 & 0 & 0 & 0 \\
\hline 8 & 19 & $\mathrm{~F}$ & + & & 2 & 0 & 1 & 1 & 0 & 0 & 0 & 1 & 0 & 0 & 0 & 0 \\
\hline 9 & 35 & M & + & & 1 & 1 & 2 & 1 & 0 & 0 & 1 & 0 & 1 & 0 & 0 & 1 \\
\hline $\begin{array}{l}\text { Mean } \\
\text { (SE) }\end{array}$ & $\begin{array}{l}24.2 \\
(2.8)\end{array}$ & & & Median & 2 & 1 & 1 & 1 & 0 & 0 & 0 & 0 & 0 & 0 & 0 & 0 \\
\hline 10 & 31 & $\mathrm{~F}$ & - & & 0 & 0 & 0 & 1 & 0 & 1 & 0 & 0 & 0 & 1 & 0 & 0 \\
\hline 11 & 28 & $M$ & - & & 1 & 0 & 0 & 0 & 0 & 0 & 0 & 1 & 0 & 0 & 0 & 0 \\
\hline 12 & 18 & $\mathrm{~F}$ & - & & 0 & 1 & 1 & 0 & 0 & 0 & 0 & 0 & 0 & 0 & 0 & 0 \\
\hline 13 & 25 & $M$ & - & & 0 & 0 & 0 & 1 & 0 & 0 & 0 & 1 & 0 & 0 & 0 & 0 \\
\hline 14 & 24 & $M$ & - & & 0 & 0 & 0 & 0 & 0 & 0 & 0 & 0 & 0 & 0 & 0 & 0 \\
\hline 15 & 25 & $\mathrm{~F}$ & - & & 1 & 1 & 0 & 0 & 1 & 1 & 0 & 0 & 0 & 1 & 0 & 0 \\
\hline 16 & 41 & $\mathrm{~F}$ & - & & 0 & 1 & 0 & 0 & 0 & 1 & 0 & 0 & 0 & 0 & 0 & 1 \\
\hline 17 & 23 & $\mathrm{~F}$ & - & & 0 & 0 & 0 & 2 & 1 & 0 & 1 & 0 & 0 & 0 & 0 & 0 \\
\hline 18 & 28 & M & - & & 0 & 1 & 0 & 1 & 0 & 0 & 0 & 1 & 1 & 0 & 0 & 1 \\
\hline $\begin{array}{l}\text { Mean } \\
\text { (SE) }\end{array}$ & $\begin{array}{l}27.0 \\
(2.1)\end{array}$ & & & Median & 0 & 0 & 0 & 0 & 0 & 0 & 0 & 0 & 0 & 0 & 0 & 0 \\
\hline
\end{tabular}

45 minutes after the challenge to evaluate changes in histamine release, and subjects recorded their sneezing, rhinorrhoea, nasal itch, and blockage by a simple scoring method two minutes after the challenge.

ASSESSMENT OF SYMPTOMS

All the subjects recorded their nasal symptoms on a four point rating scale from 0 to $3(0=$ no symptoms, $1=$ mild, $2=$ moderate, and $3=$ severe). Thus, for each study visit a maximum score of 12 was possible derived from summation of the symptoms of sneezing, rhinorrhoea, nasal itch, and blockage.

NASAL CHALLENGE

AMP and GMP (Sigma Chemicals, St Louis, Missouri, USA) were dissolved in $0.9 \% \mathrm{w} / \mathrm{v}$ normal saline to achieve a concentration of $50 \mathrm{mg} / \mathrm{ml}$, divided into small aliquots, and frozen at $-20^{\circ} \mathrm{C}$. After thawing, AMP, GMP, or saline solution was sprayed using a hand held pump spray calibrated to deliver 130 (9) $\mathrm{ml}$ per puff. The pump spray was placed in one of the nostrils, while occluding the contralateral nostril, and activated once during quiet inspiration. The procedure was then repeated in the opposite nostril. At the concentration used this method delivered a total dose of approximately $6.5 \mathrm{mg}$ AMP and GMP equally divided between the two nostrils. The dose of $6.5 \mathrm{mg}$ used in the present investigation was chosen on the basis of our previous dose-response studies with AMP in subjects with rhinitis; this dose elicited nasal symptoms in all the subjects studied. ${ }^{3}$

NASAL LAVAGE AND SAMPLE PROCESSING

Each subject was instructed to tilt his neck backwards, to hold his breath, and to refrain from swallowing. Prewarmed normal saline $(2.5 \mathrm{ml} /$ nostril $)$ was then instilled into each nostril and, after 10 seconds, the subject flexed his neck and expelled the mixture of mucus and saline into a conical polypropylene tube. Samples were immediately filtered to remove mucus and centrifuged at $400 \mathrm{~g}$ for 10 minutes at $4^{\circ} \mathrm{C}$ to separate the cells from the fluid. The supernatants were then removed, aliquoted into plastic tubes, and frozen at $-70^{\circ} \mathrm{C}$ for subsequent analysis.

\section{MEASUREMENT OF HISTAMINE}

Histamine in nasal lavage fluid was measured by radioimmunoassay using a commercially available kit (Immunotech SA, Marseille, France). The assay was performed according to the manufacturer's instructions. Each sample was assayed in duplicate and the results were expressed as $\mathrm{ng} / \mathrm{ml}$ of lavage fluid. The lowest limit of detection was $0.02 \mathrm{ng} / \mathrm{ml}$.

\section{ANALYSIS OF DATA}

Baseline measurements of histamine levels on the different challenge days were compared between days using Friedman's two-way ANOVA procedure. To assess differences in histamine levels over time following nasal challenge with AMP, GMP or placebo, the area under the curve (AUC) was calculated for each challenge period and compared using Friedman's two way ANOVA test followed by Wilcoxon's signed rank test for paired data where appropriate. Median differences and $95 \%$ confidence intervals for the between group comparisons were calculated. Friedman's two way ANOVA and Wilcoxon's signed rank test were also used for comparisons of the effects of AMP, GMP, and placebo on symptom scores. Differences between allergic and non-allergic subjects were investigated using the Mann-Whitney U test.

\section{Results}

SYMPTOM SCORES TO NASAL PROVOCATION

Nasal provocation with AMP elicited a significant increase in symptom scores whereas no symptoms were reported on the placebo and GMP study days (table 1). A significant difference in AMP induced symptom scores was found between subjects with allergic rhinitis and non-allergic individuals, the median 


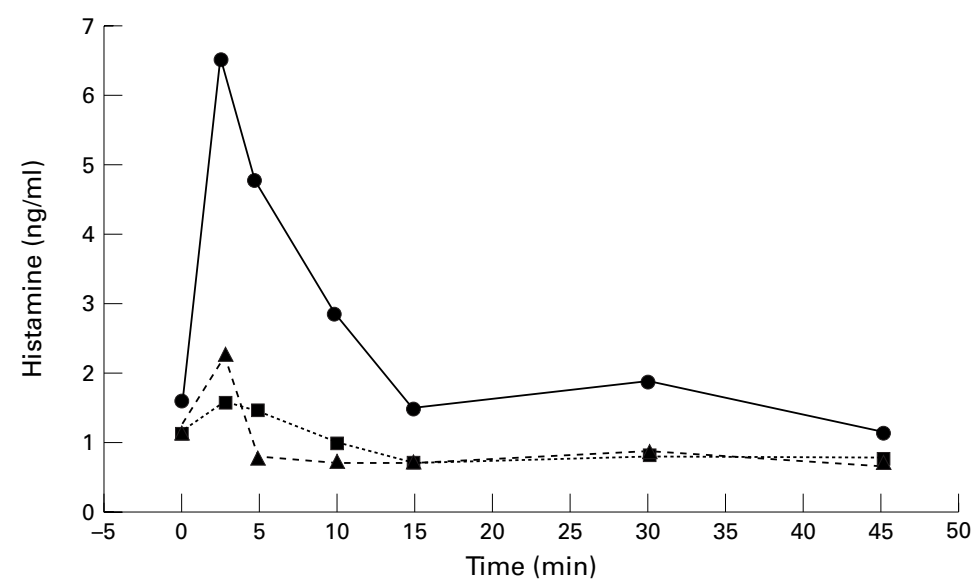

Figure 1 Time course of the changes in the median levels of histamine after nasal challenge with $A M P(\bullet), G M P(\mathbf{\Delta})$, and placebo (-) in the allergic subjects studied $(n=9)$.

(range) value for their symptom scores being 5 $(3-10)$ and $1(0-2)$, respectively $(\mathrm{p}<0.01)$.

HISTAMINE LEVELS IN NASAL LAVAGE FLUID There was no significant difference in the baseline levels of histamine in the nasal lavage fluid between any of the three challenge days.

No significant changes in histamine levels were seen after challenge with GMP and placebo at any of the time points studied (figs 1 and 2). Nasal provocation with AMP elicited a significant $(p<0.02)$ fourfold rise in histamine with a peak response at three minutes in allergic but not in control subjects, their median (range) baseline value of $1.62(0.44-6.99) \mathrm{ng} /$ $\mathrm{ml}$ increasing to $6.45(0.81-16.17) \mathrm{ng} / \mathrm{ml}$ (fig 1). In contrast, no significant increase in histamine concentrations on AMP challenge was seen in non-allergic controls (1.13 (0.29$4.25) \mathrm{ng} / \mathrm{ml}$ and $0.97(0.31-5.89) \mathrm{ng} / \mathrm{ml}$ at baseline and three minutes after challenge, respectively; fig 2 ).

When the effect of AMP was expressed as the AUC, statistically significant differences compared with GMP and placebo were found in the allergic subjects, the median AUC value of 100.1 (30.3-267.9) $\mathrm{ng} / \mathrm{ml} / \mathrm{min}$ being significantly higher than the values of 37.2 (7.2$127.5) \mathrm{ng} / \mathrm{ml} / \mathrm{min}(\mathrm{p}<0.01)$ and $43.5 \quad(9.8$ 69.4) $\mathrm{ng} / \mathrm{ml} / \mathrm{min}(\mathrm{p}<0.01)$ obtained on GMP and placebo study days, respectively. The

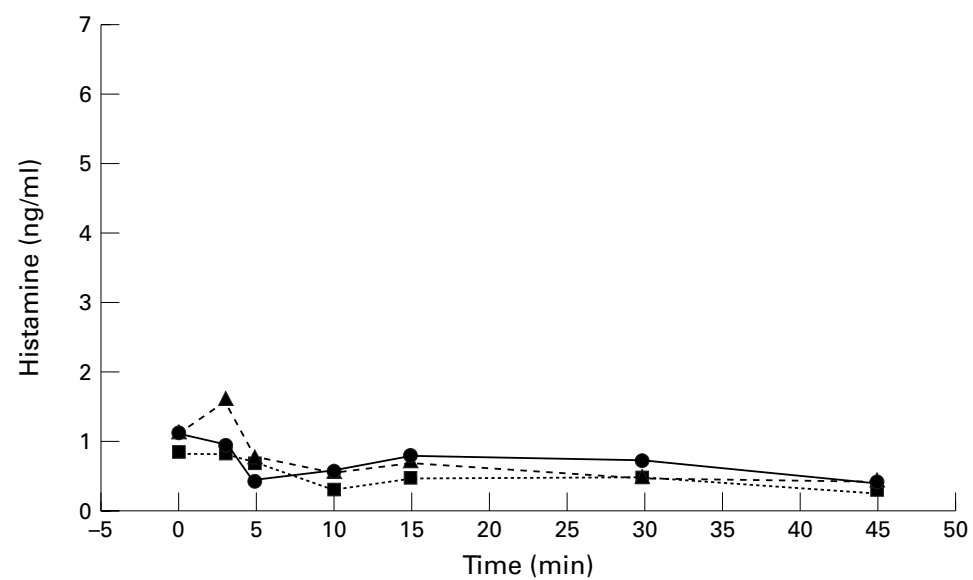

Figure 2 Time course of the changes in the median levels of histamine after nasal challenge with $A M P(\bullet), G M P(\mathbf{\Delta})$, and placebo (-) in the non-allergic subjects studied $(n=9)$. median differences (95\% CI) between AMP and GMP and AMP and placebo were 40 (19.1) and 76 (34.1), respectively. No significant difference in the AUC was found between GMP and placebo.

\section{Discussion}

Nasal provocation with AMP elicits a substantial increase in symptom scores in subjects with allergic rhinitis. We have also shown that AMP provokes histamine release in the nasal lavage fluid of allergic subjects. These findings indicate that allergic subjects are more prone to release histamine in response to AMP than non-allergic subjects. A degree of selectivity for the adenine moiety is suggested by the finding that, in the subjects studied, the same dose of the purine nucleotide GMP had no measurable effect on the nasal symptom score and on histamine levels released in the lavage fluid upon nasal provocation.

Histamine levels in the lavage fluid increased following nasal provocation with AMP, suggesting in vivo activation of nasal mast cells. Although histamine is an indicator of mast cell activation, ${ }^{8}$ our findings do not discriminate the cellular origin. The rise in histamine levels may also implicate the basophils in the response. Compared with our findings with AMP, allergen provocation elicits larger increases (up to 10 times) in the levels of histamine in nasal lavage fluid. ${ }^{9}{ }^{10}$ Since adenosine is rapidly taken up into cells and metabolised, it seems likely that this nucleoside activates mast cells or basophils restricted to the airway surface and not those found deeper in the nasal mucosa, as might be the case for a more stable stimulus such as allergen.

The significant rise in histamine levels after local AMP challenge is in keeping with a number of in vitro and in vivo studies. Adenosine and synthetic analogues active at A2 purinoceptors markedly enhance histamine release from peripheral blood basophils and mast cells dispersed from human lung tissue. ${ }^{4-6} \mathrm{~A}$ significant rise in bronchoalveolar lavage fluid levels of histamine and tryptase was also reported in allergic asthmatic subjects following endobronchial AMP challenge. ${ }^{7}$

Nasal challenge with AMP elicits an immediate rise in histamine levels in the nasal lavage fluid of allergic individuals, but not in nonallergic controls. This indicates that the atopic status may be an important determinant of enhanced adenosine induced histamine release. In this context, it is of interest that adenosine potentiates the release of histamine when human mast cells are immunologically primed in vitro. ${ }^{56}$ In addition, atopic subjects are more responsive than non-atopic subjects to inhaled AMP than they are to methacholine. ${ }^{11}$ Increased adenosine responsiveness in the form of heightened histamine release has recently been shown in sensitised mice compared with non-sensitised controls. ${ }^{12}$

The causes for the enhanced histamine releasability in atopic individuals have not yet been defined. It is possible that adenosine potentiates mediator release in allergic individuals by interacting with cytokine "primed" 
mast cells/basophils on the surface of their inflamed airways. It is known that proinflammatory cytokines such as interleukin (IL)-3, IL-4, IL-5, and granulocyte-macrophage colony stimulating factor (GM-CSF) are usually present in the nasal mucosa of allergic individuals. ${ }^{13}$ Cytokines have a profound influence on basophil and mast cell function; IL-3 is the most potent upregulator of basophil releasability in vitro and in vivo ${ }^{14}{ }^{15}$ and stem cell factor (SCF), the ligand of the c-kit receptor, is known to enhance the release of histamine from both human lung mast cells and basophils. ${ }^{1617}$ In addition, administration of IL-2 and IL-4, alone and in combination, potentiates histamine release from human basophils ex vivo. ${ }^{18}$ In view of these observations, it is tempting to suggest that the presence of proinflammatory cytokines within the airway mucosa may be the cause for the reported cell releasability. Thus, the AMP induced nasal responses in our atopic subjects may unveil airway mast cell priming in vivo, and be used as a potential new marker of allergic inflammation which may be useful in assessing the value of anti-inflammatory drugs.

These studies were supported by a research grant from the University of Catania (Grant $60 \%$ ).

1 Richardson PJ. Blocking adenosine with antisense. Nature 1997;385:684-5.

2 Polosa R, Holgate ST. Adenosine bronchoprovocation: a promising marker of allergic inflammation in asthma? Thoprax 1997:52:919-23.

3 Crimi N, Polosa R, Mistretta A. Mechanisms of the effector function of adenosine in asthma and rhinitis. Drug Develop Res 1993;28:322-7.

4 Church MK, Holgate ST, Hughes PJ. Adenosine inhibits and potentiates IgE-dependent histamine release from human basophils from an $\mathrm{A}_{2}$-receptor mediated mechanism. Br F Pharmacol 1983;80:719-26.
5 Hughes PJ, Holgate ST, Church MK. Adenosine inhibits and potentiates IgE-dependent histamine release from human lung mast cells by an $\mathrm{A}_{2}$-purinoceptor mediated mechanism. Biochem Pharmacol 1984;33:3847-52.

6 Peachell PT, Columbo M, Kagey-Sobotka A, et al. Adenosine potentiates mediator release from human lung mast cells. Am Rev Respir Dis 1988;138:1143-51.

7 Polosa $\mathrm{R}, \mathrm{Ng}$ WH, Crimi $\mathrm{N}$, et al Release of mast cell-derived mediators after endobronchial adenosine challenge in asthma. Am f Respir Crit Care Med 1995;151:6249.

8 Proud D, Bailey GS, Naclerio RM, et al. Tryptase and histamine as markers to evaluate mast cell activation during responses to nasal challenge with allergen, cold dry air, and hyperosmolar solutions. f Allergy Clin Immunol 1992;89: 1098-110.

9 Creticos PS, Adkinson NF, Kagey-Sobotka A, et al. Nasal challenge with ragweed pollen in hay fever patients. $\mathcal{f}$ Clin Invest 1985;76:2247-53.

10 Castells M, Schwartz LB. Tryptase levels in nasal lavage fluid as an indicator of the immediate allergic response. $f$ Allergy Clin Immunol 1988;83:348-55.

11 Phillips GD, Ng WH, Church MK, et al. The response of plasma histamine to bronchoprovocation with methacholine, AMP, and allergen in atopic non asthmatic subjects. Am Rev Respir Dis 1990;141:9-13.

12 Hoffman HM, Marquardt DL. The effect of adenosine on histamine release from allergen-sensitized mouse lung tissue. F Allergy Clin Immunol 1997;99(Part 2):S89.

13 Durham SR, Ying S, Varney VA, et al. Cytokine mRNA expression for IL-3, IL-4, IL-5 and GM-CSF in the nasal mucosa after local allergen provocation: relationship to tissue eosinophilia. F Immunol 1992;148:2390-4.

14 Merget RD, Maurer AB, Koch U, et al. Histamine release from basophils after in vivo application of recombinant human IL-3 in man. Int Arch Allergy Appl Immunol 1990;92:366-74.

15 MacGlashan DW, Hubbard WC. IL-3 alters free arachidonic acid generation in $\mathrm{C} 5 \mathrm{a}$ stimulated human basophils. f Immunol 1993;151:6358-69.

16 Columbo M, Horowitz EM, Botana LM, et al. The human recombinant $c$-kit receptor ligand, rhSCF, induces mediator release from human cutaneous mast cells and enhances IgE-dependent mediator release from both skin mast cell and peripheral blood basophils. F Immunol 1992;149:599608.

17 de Paulis A, Ciccarelli A, Cirillo R, et al. Modulation of human lung mast cell function by the $c$-kit receptor ligand. Int Arch Allergy Appl Immunol 1992;99:326-9.

18 White MV, Igarashi Y, Emmery BE, et al. Effects of in vivo administration of IL-2 and IL-4, alone and in combination, on ex vivo human basophil histamine release. Blood 1992;76:1491-5. 